Linguagem em (Dis)curso - LemD, v. 9, n. 1, p. 107-130, jan./abr. 2009

\title{
A TESE DA PRIMAZIA DA METÁFORA, DEFESA E PROBLEMATIZAÇÃO: UM ESTUDO A PARTIR DE VICO*
}

Alessandro Zir**

\begin{abstract}
Resumo: Este artigo defende, com base no pensamento do filósofo italiano moderno Giambattista Vico, a tese que aponta a linguagem poética e metafórica como sendo a linguagem primeira. Considerando contribuições de alguns autores atuais para o tema, se apontará igualmente para a contemporaneidade da abordagem de Vico. A noção da linguagem metafórica como linguagem primeira foi formulada por Giambattista Vico na sua obra Principii di Scienza Nuova. De acordo com ele, a linguagem de uma comunidade surge de um contacto, carregado de fantasia e imaginação, entre tudo o que está imediatamente próximo aos seres humanos concretos, como suas emoções e seus corpos, que não são derradeiramente conhecidos por ele, e as coisas de um mundo externo também desconhecido. A 'linguagem abstrata' e a distinção entre o metafórico e o literal surgem apenas mais tarde, quando esse enraizamento dos significados na eclosão imaginativa de uma cultura específica passa a ser esquecido e é tomado como pertencendo apenas às coisas nelas mesmas, objetivamente.
\end{abstract}

Palavras-chave: conhecimento; linguagem; metáfora; retórica; significado.

\footnotetext{
* Agradeço ao Conselho Nacional de Desenvolvimento Científico e Tecnológico (CNPq), Brasil, pelo suporte recebido para a realização do projecto de pesquisa "Vico e a visão tradicional da retórica", no âmbito do qual o presente artigo foi inicialmente escrito, enquanto me encontrava sob a orientação da professora Anna Carolina K. P. Regner no Departamento de Filosofia da UFRGS.

** Doutorando no Interdisciplinary Programme da Dalhousie University (Halifax, Canada). Bolsista Capes de doutorado pleno no exterior e membro do Grupo Interdisciplinar em Filosofia e História das Ciências (GIFHC) do Instituto Latino-Americano de Estudos Avançados da UFRGS. E-mail: <azir@dal.ca>.
} 


\section{INTRODUÇÃO}

O objetivo deste artigo é sustentar, com base no pensamento do filósofo italiano moderno Giambattista Vico, a tese que caracteriza a linguagem poética e metafórica como sendo a linguagem primeira considerando, também, a contemporaneidade da abordagem de Vico, mediante comparações com autores atuais. Oposta a essa tese que pretendemos defender está aquela outra que afirma ser a linguagem metafórica um desvio da linguagem dita literal, e, portanto, posterior à linguagem literal. A tese da linguagem metafórica como linguagem primeira encontra-se formulada por Giambattista Vico na sua obra intitulada Principii di Scienza Nuova, cuja primeira edição data de 1725. Essa tese será defendida, mais tarde, também por pensadores como Nietzsche, e contemporaneamente por filósofos como Hans-Georg Gadamer e Paul Ricoeur. Enquanto as posições desses últimos autores são bastante comentadas na literatura sobre o tema, as considerações de Vico são bem menos exploradas, e um dos objetivos principais desse artigo é resgatá-las.

O filósofo David Cooper, num capítulo do seu livro The primacy of metaphor (1986), faz uma objeção às teses da primazia da linguagem metafórica com relação à linguagem literal. De acordo com ele, aqueles que defendem a tese da primazia da metáfora (Cooper refere-se explicitamente a Gadamer) afirmariam que, na era inicial da linguagem, não haveria nada em virtude do que se pudesse julgar a transferência de uma palavra de determinadas coisas particulares para outras ${ }^{1}$. Ele questiona então se poderia haver uma linguagem ontologicamente inicial, em que nada houvesse para determinar a 'aplicação natural de palavras' como corretas ou incorretas. Sua resposta é a de que não seria possível

\footnotetext{
1 'During that period, then, there was nothing — 'meanings' or whatever — in virtue of which 'natural' applications of words could be determined as correct" (COOPER, 1986, p. 268). Mais adiante: "For an utterance to be 'grounded on the principle of metaphor', we might say, not only must it not perform a 'subsuming act', but it must be one which could not be used to perform a 'subsuming act' by any speaker of the Ursprache" (COOPER, 1986, p. 272). "In the Urzeit, however, the consciousness, apparatus, and purposes required for an utterance to be used in the performance of a 'subsuming act' are missing. That is why every utterance of that era obeys 'the principle of metaphor"' (COOPER, 1986:, p. 272). "For the theses of the primacy of metaphor to be right, there had to be nothing, during the Urzeit, in virtue of which application could be determined as correct, or utterances as true or false" (COOPER, 1986, p. 277).
}

ZIR - A tese da primazia da metáfora, defesa e problematização... 
tal linguagem inicial, pois ela não teria como assegurar a sobrevivência de nenhum tipo de comunidade real. ${ }^{2}$

Este trabalho, contra posições como a de Cooper, defende as teses de Vico sobre a primazia da metáfora. Embora Cooper se detenha na argumentação de Gadamer, a qual considera como a melhor tentativa de estabelecer a tese da primazia da metáfora, ele cita Vico explicitamente junto com outros autores, que considera como desenvolvendo uma especulação de apelo emocional não satisfatória:

Entre outros que eu poderia mencionar estão os seguintes: [...] e a alegação de Vico de que o pensamento originalmente deve ter sido poético e metafórico no sentido de 'criar as entidades' que a ciência mais tarde irá definir e dissecar. Especulações como essa exercem um apelo imaginativo; para que esse apelo seja genuíno, alguma coisa como a versão de Gadamer da tese da primazia da metáfora deve ser elaborada. (COOPER, 1986, p. 263 - tradução nossa)

Mas é preciso questionar se a crítica de Cooper faz jus à argumentação de Vico. Por exemplo, para Vico, em verdade, ao contrário de como o interpreta Cooper, afirmar que a linguagem de uma dada comunidade é poética e fantástica não implica em afirmar que não existam critérios que determinem a utilização de palavras por essa comunidade. Uma linguagem pode ser dita poética e fantástica e não obstante existirem nela tais critérios, os quais seriam suficientes para assegurar muito bem a sobrevivência da comunidade que a utiliza. Para Vico, as metáforas estão ligadas ao modo de pensar e de viver dos homens num dado contexto, não podendo ser consideradas meramente arbitrárias ou aleatórias. Enfim, para Vico, a linguagem metafórica gera, por si mesma, critérios de correção (sem para isso depender de nenhum tipo de 'linguagem mais literal' ou abstrata) - eis aqui, em verdade, o ponto de divergência para com autores como Cooper.

\footnotetext{
2 "The question now becomes: could there be a language, like Gadamer's Ursprache, where there is nothing to determine the 'natural' applications of words as correct or incorrect?", p. 268. "Granted that the Urspracher do not engage in classification and categorization as we do, can it be that none of their utterances are properly described in such terms? Could there be a linguistic community none of whose utterances deserve such characterizations? I want to reply that such a community could only be a fantastic one" (COOPER, 1986, p. 272-273).
} 
O que confere um caráter primordialmente metafórico à linguagem para pensadores como Vico não é nenhuma ausência inicial de critérios para o uso de palavras, mas o fato de que uma linguagem nasce (ver mais adiante a seção 2, A gênese metafórica do mundo das naçôs) para os homens de uma comunidade no choque entre uma natureza interna, cuja origem última lhes permanece inacessível, e uma natureza externa, cuja origem última também não lhes é acessível. Para Vico, a linguagem abstrata, e a distinção entre o metafórico e o literal só surgem mais tarde, quando os traços dessa eclosão começam a ser progressivamente esquecidos e supostos como pertencendo apenas às coisas nelas mesmas, objetivamente.

Fora a contraposição a Cooper, procuramos, por outro lado, comparar a análise de Vico da linguagem poética com outras análises da linguagem metafórica atuais, como, por exemplo, a de Glucksberg e Keysar (1990), que desenvolvem a idéia de que as metáforas são uma forma de categorização e têm um papel importante na criação de novos sentidos. Também relacionamos Vico com Lakoff e Johnson (1980), os quais consideram que concebemos o mundo e nós mesmos através da linguagem com base em metáforas oriundas de nossas condições físicas e contextos culturais. Pareceria comum a Vico e a esses dois últimos autores a ideia de que, na linguagem metafórica, há certamente critérios de correção, mas eles não podem ser ditos puramente objetivos, pois estão vinculados à nossa condição última, de seres sensíveis imersos numa cultura. Nosso artigo começa com uma caracterização da linguagem metafórica, feita justamente a partir de uma correlação de Vico com Glucksberg e Keysar, a qual visa explicitar o poder criativo da metáfora, sua capacidade de gerar novos significados. Em seguida, vamos enfocar propriamente a questão da primazia da metáfora, de como a metáfora está na gênese dos mundos habitados pelas comunidades humanas, do mundo das nações. Exploraremos, então, o mundo das nações através de três tópicos: o primado do social, a atividade perceptiva e os protótipos. $\mathrm{Na}$ análise do segundo tópico será feita a comparação de Vico com Lakoff e Johnson. Nas Considerações Finais, traremos para o debate também algumas afirmações de Ricoeur sobre a importância de se entender a capacidade da metáfora de gerar novos significados no sentido de essa ser a mesma capacidade que faz nascer a linguagem.

ZIR - A tese da primazia da metáfora, defesa e problematização... 


\section{CARACTERIZAÇÃO DA LINGUAGEM METAFÓRICA}

No capítulo "Lógica poética", do livro segundo da Ciência Nova, Vico afirma que, de todos os tropos, "a mais luminosa, e porque mais luminosa mais necessária e mais frequente é a metáfora, que é tanto mais louvada quanto às coisas insensatas dá senso e paixão" (1953, \404)33. Fazendo uso de metáforas, os poetas deram a determinados corpos físicos "o ser de determinadas substâncias animadas", dotadas de capacidades sensíveis e emocionais, criando as fábulas $(1953, \$ 404)^{4}$. Jogando-se com o significado do termo latino insensatu, podemos afirmar, à luz do que diz Vico, que as metáforas dão sentido ao que não tem sentido e sentimento ao que é insensível. Elas transportam, por assim dizer, o sentido de coisas de um determinado tipo a outras coisas diferentes. Ao fazer isso, cada metáfora é uma pequena fábula.

A princípio não diferindo da tradição aristotélica, Vico coloca como sendo a propriedade fundamental da metáfora o estabelecer o significado de algo em termos de outro algo diferente. Vimos também, na passagem já citada, que ele afirma ser cada metáfora uma pequena fábula. As fábulas, por sua vez, são definidas como "gêneros fantásticos", que falam alegoricamente através de mitologias (1953, $\$ 403)^{5}$. Pela etimologia, alegoria significa 'falar de outro modo', (allii, de outro modo, agoréuein, falar).

Vico afirma que as alegorias não dão às fábulas significados análogos, mas "significados univocos", simples e não ambíguos, "abrangendo diversos particulares sob um gênero poético", pelo que são chamadas no latim de diversiloquia, isto é, "falar abrangendo em um conceito geral diversas espécies de homens, fatos ou coisas" (1953,

\footnotetext{
3 "Di questa logica poetica sono corollari tutti i primi tropi, de'quali la più luminosa e, perchè più luminosa, più necessaria e più spessa è la metafora, ch'allora è vieppiù lodata quando alle cose insensate ella dà senso e passione [...]." A tradução das citações de Vico ao longo do corpo do trabalho é de nossa responsabilidade, sendo que os trechos originais respectivos constarão sempre em rodapé.

4 “[...]i primi poeti dieder a' corpi l'essere di sostanze animate, sol di tanto capaci di quanto essi potevano, cioè di senso e di passione, e sì ne fecero le favole; talchè ogni metafora sì fatta vien ad essere uma picciola favoletta".

5 "Quindi le mitologie devon essere state i propri parlari delle favole [...]; talchè essendo le favole, come sopra si è dimonstrato, generi fantastici, le mitologie devono essere estate le loro proprie allegorie".
} 
\$210) ${ }^{6}$. Podemos pensar as metáforas exatamente da mesma maneira, como estabelecendo significados unívocos, simples e predicando diretamente uma coisa de outra - não no sentido de que os significados dos termos que compõem a metáfora tivessem que ser totalmente igualados, mas no sentido de que a metáfora estabelece uma predicação entre esses termos, tal que gera, num outro nível, num nível superior, uma nova classificação, ao promover, alegoricamente, um outro modo de falar.

Podemos ver, assim, a contemporaneidade da abordagem de Vico. Num estudo importante que resgata as principais contribuições contemporâneas em língua inglesa sobre a metáfora, Glucksberg e Keysar (1990) afirmam que, quando falo metaforicamente de A em termos de $\mathrm{B}$, não digo que $\mathrm{A}$ é semelhante a $\mathrm{B}$, mas vinculo diretamente $\mathrm{A}$ a $\mathrm{B}^{7}$. Ao contrário do símile, que estabelece uma analogia do tipo "A é como B", a metáfora diz: "A é B". Assim, seguindo esses autores, podemos afirmar que, quando dizemos "meu trabalho é uma prisão", na verdade não queremos dizer que ele se parece com uma prisão, mas que ele deve ser incluído na classe das coisas que confinam a nossa vontade, são desagradáveis e difíceis de escapar, em relação às quais "prisão" funciona como um exemplo prototípico.

Para explicitar o caráter unívoco e predicativo das fábulas, logo em seguida à passagem já citada, Vico dá dois exemplos que, de certa

\footnotetext{
6 “E quest'ultima degnità, in séguito dell'antecedenti, è 'l principio delle vere allegorie poetiche, che alle favole davano significati univoci, non analogi, di diversi particolari compresi sotto i loro generi poetici: le quali perciò si dissero $<<$ diversiloquia $>>$, cioè parlari comprendenti in um general concetto diverse spezie di uomine o fatti o cose." Também: "Il qual nome [allegorie], come si è nelle Degnità osservato, ci venne diffinito $<<$ diversiloquium $>>$, in quanto, com identità non di proporzione ma, per dirla alla scolastica, di predicabilità, esse significano le diverse spezie o i diversi individui compresi sotto essi generi: tanto che devon avere uma significazione univoca, comprendente uma ragion comune alle loro spezie o individui’ $(1953, \$ 403)$.

${ }^{7}$ Glucksberg e Keysar não são autores cuja contribuição tenha gerado grande repercussão na vasta literatura sobre a metáfora. $\mathrm{O}$ trabalho desses autores, entretanto, segue na linha de uma tradição bastante reconhecida de reflexão sobre a metáfora em língua inglesa, que remonta a autores como I. A. Richards (1981) e Max Black (1981), e conduz ao famoso trabalho de Lakoff e Johnson (1980). O artigo de Glucksberg e Keysar destaca-se, ainda, por sua singular clareza na articulação das contribuições oriundas dessa tradição. Seu artigo não apenas discute essa tradição como infere dela uma definição de metáfora, a qual os autores pretendem testar em termos mais empíricos, dentro de uma psicologia de linha cognitivista, e superando inclusive Lakoff e Johnson. Por sua clareza e atualidade, tal definição nos pareceu extremamente adequada para uma contraposição com Vico, tendo em vista mostrar a contemporaneidade da posição do filósofo italiano do século XVIII.
}

ZIR - A tese da primazia da metáfora, defesa e problematização... 
forma, vão no sentido em que Glucksberg e Keysar compreendem a metáfora: Aquiles, personagem fantástico que representa a idéia do valor comum a todos os fortes, e Ulisses, que nos dá a idéia de prudência

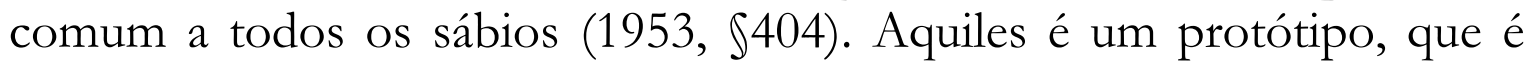
predicado de homens particulares vinculando-os a uma categoria específica. Anteriormente, Vico já havia dado o seguinte exemplo: quando, "dois mil anos após o dilúvio universal", os homens da terra foram atraídos para contemplar o céu "pela força dos raios surgidos da atmosfera seca", deram a ele a sua própria natureza de "gigantes robustos", que "berrando e protestando expressavam suas violentíssimas paixões", "chamando-o Zeus". Não era que o céu, objeto físico e inanimado, fosse parecido com um ser animado e violento - mais que isso, ele pertencia à classe dos "gigantes robustos", representada na sentença pelo protótipo "Zeus". A metáfora, portanto, estabelece o significado de A em termos de $\mathrm{B}$, predicando $\mathrm{B}$ de $\mathrm{A}$. Os dois termos permanecem tendo núcleos de significados diferentes: no exemplo dado, A representa aquele espaço acima da minha cabeça onde flamejam os raios e estrondam trovões; B representa os 'meus' próprios anseios de ser animado, que me conduzem a berrar e protestar. Através da metáfora, esses núcleos são ampliados, e, em parte, subsumidos a uma nova classificação de nível superior.

Assim, tanto Vico quanto Glucksberg e Keysar enfatizam que a metáfora é geradora de novos significados e sentidos. Por isso, ela é mais do que uma mera comparação, ao contrário do que normalmente se pensa. No parágrafo 403, já referido, Vico afirma também que as alegorias estão baseadas na "predicabilidade" e não na "proporção". Glucksberg e Keysar (1990, p. 11) consideram dois tipos possíveis de comparações: as literais e as não literais (metafóricas). De acordo com esses autores, as comparações literais são aquelas em que as propriedades a serem compartilhadas pelas coisas se derivam de uma categorização implícita, como no caso "limões são como limas", cuja classe em questão

\footnotetext{
8 "Com tali nature si dovettero ritruovar i primi autori dell'umanità gentilesca quando — dugento anni dopo il diluvio per lo resto del mondo e cento nella Mesopotamia [...] il celo finalmente folgorò, tuonò com folgori e tuoni spaventosissimi , come dovett'avvenire per introdursi nell'aria la prima volta um'impressione sì violenta. [...] E perché in tal caso la natura della mente umana porta ch'ella atribuisca all'effeto la sua natura, [...] e la natura loro era, in tale stato, d'uomini tutti robuste forze di corpo, che urlando, brontolando, spiegavano le loro violentissime passioni; si finsero il cielo esser um gran corpo animato, che per tal aspetto chiamarono Giove [...]".
} 


\section{4}

é a das frutas cítricas, à qual ambas as coisas pertencem. Seguindo o seu raciocínio, no caso de comparações não literais, do tipo "cigarros são como bombas-relógio", determinadas propriedades da coisa 'cigarro' são trazidas à tona quando ela é incluída na classe das coisas que são potencialmente mortíferas, representada através do protótipo 'bombasrelógio'. Na comparação literal, cada um dos termos, 'limões' e 'limas', refere-se como um nome a coisas colocadas lado a lado, já que pertencem a uma mesma classe já estabelecida e implícita - pelo que a comparação literal é pouco informativa. Ao contrário, na comparação não literal, bomba-relógio é um nome que se refere a uma coisa que funciona como um protótipo, promovendo explicitamente uma categorização. Por isso, se eliminamos o ‘como’ da predicação não literal, ela ganha mais força, ficando evidente o seu carácter metafórico, predicativo e possivelmente verdadeiro: "cigarros são bombas-relógio".

De acordo com o que vimos até aqui, as metáforas estabelecem o significado de algo em termos de outro algo diferente, que funciona como um protótipo, num processo de categorização. Nas palavras de Vico, elas dizem respeito mais à "predicabilidade" do que à "proporção" (1953, \403). São um tipo de predicação que gera uma classificação de nível superior, que expande o significado trivial das coisas dadas na sentença.

Antes de encerrarmos a caracterização da linguagem metafórica, convém ainda distinguir a predicação levada a cabo pela sentença metafórica e a levada a cabo pela sentença literal. No segundo caso, a categoria comparece ela mesma na sentença, e não através de um protótipo. Exemplo: oftalmologistas são médicos. Além disso, a predicação literal não gera novas classificações, de nível superior, que expandiriam o significado dos termos. A predicação literal atua no nivel das classificações já estabelecidas. No caso específico de Vico, os protótipos têm uma importância fundamental porque as categorias e as classificações começam a ser estabelecidas na linguagem através de experiências concretas, particulares, que funcionam como figuras, exemplos de classes ainda não nitidamente estabelecidas. Para Vico, os termos abstratos, por outro lado, designam classificações já anteriormente estabelecidas, já cristalizadas na linguagem como gêneros e espécies. Esses pontos serão melhor explicados na secção a seguir, quando tratarmos propriamente da questão da primazia da linguagem metafórica, de como a metáfora está na gênese do mundo de uma nação, 
inicialmente muito vivo e tumultuoso, mas que com o tempo vai assumindo um caráter cada vez mais abstrato e enrijecido.

Uma última consideração diz respeito a que a caracterização da metáfora aqui desenvolvida, que Vico procura explorar vendo o que nele há de mais contemporâneo, não se restringe a metáforas nominativas. Glucksberg e Keysar (1990, p. 16) afirmam ter-se focado em metáforas nominativas, ao desenvolver a sua definição da metáfora como categorização através de protótipos. Não obstante, segundo eles próprios, sua avaliação pode ser estendida em princípio à outra classe importante de metáforas, a saber, as referentes a verbos. O exemplo que eles dão é o seguinte: "Ela pulou em sua bicicleta e voou para casa." Nesse caso, 'voar' pode ser considerada uma "ação prototípica" da categoria das ações extremamente velozes e diretas. No parágrafo 181 da Ciência Nova, Vico afirma que os homens comuns costumam dizer "estar o ímã enamorado do ferro". É um exemplo de metáfora verbal, o qual pode ser entendido da seguinte maneira: "estar enamorado", na sentença em questão, funciona como um exemplo prototípico da categoria das ações (ou paixões) que compelem as coisas a se unirem e permanecerem unidas.

\section{A GÊNESE METAFÓRICA DO MUNDO DAS NAÇÕES}

Vico vincula a essência das coisas ao seu surgimento, enraizando-a no tempo e no espaço. Ele define natureza e propriedade fundamental de algo como sendo "o nascimento desse algo num certo tempo e de uma certa maneira", de tal modo que, se houvesse repetição, a coisa teria de se desenvolver exactamente como se desenvolveu da primeira vez $(1953, \$ 147)^{9}$. As propriedades essenciais, sem as quais as coisas deixam de ser elas mesmas, devem ser "produto da modificação ou maneira através da qual essas coisas nascem" (1953, \$141-8). ${ }^{10}$ Para dizer que

\footnotetext{
9 "Nature di cose altro non è che nascimento di esse in certi tempi e com certe guise, le quali sempre che sono tali, indi tali e non altre nascon le cose".

10 'Le proprietà inseparabili da' subbietti devon essere produtte dalla modificazione o guisa com che le cose son nate; per lo che esse ci posson avverare tale e non altra essere la natura o nascimento di esse cose".
} 


\section{6}

realmente conheço algo, teria de ter acesso a todos os elementos-chave envolvidos no seu ato de eclosão. Decorre disso que aquilo que não se cria, não se pode conhecer completamente.

Portanto, não seria possível uma ciência do mundo natural para o homem. Essa seria possível somente para Deus. "[...] a qualquer um que reflita, deve produzir espanto como todos os filósofos seriamente planearam conseguir a ciência deste mundo natural, do qual, porque Deus o fez, só ele tem a ciência” (1953, §331). ${ }^{11}$ Mas por outro lado, para Vico, num outro sentido, é possível também dizer que o homem é criador das coisas do mundo, na medida em que essas coisas comparecem metaforicamente no mundo das nações (e como tal, o homem poderá conhecê-las).

No segundo capítulo da Lógica poética, no parágrafo 405, Vico afirma que "em todas as línguas a maior parte das expressões envolvendo coisas inanimadas são feitas através do transporte do corpo humano, das suas partes, dos sentidos humanos e das paixões humanas." 12 Isto é, para ele, a maioria das expressões referentes às coisas inanimadas são metafóricas, tendo seu sentido transposto do corpo humano e de suas partes, ou dos sentidos e das emoções humanas. Segue-se uma lista de exemplos, dos quais citamos alguns: dizemos 'cabeça' para significar topo ou princípio; 'boca' para significar qualquer tipo de abertura; falamos dos 'dentes' do arado, do serrote e do pente; falamos da 'garganta' de rios e montanhas; falamos de 'coração' para designar o centro de alguma coisa; falamos da 'carne' das frutas; o sol 'sorri' sobre nós; o vento 'assobia'; as ondas 'murmuram'; e um corpo às vezes 'geme' quando colocado sob um grande peso. Assim, Vico, no final do mesmo parágrafo, aposta na verdade da "metafísica fantástica", cujo lema é homo non intelligendo fit omnia", e segundo a qual "o homem [...] não entendendo, de si mesmo faz as coisas, e transformando a si mesmo, torna-se elas" (1953, \405). ${ }^{13}$ O não entender aqui refere-se ao fato de o

\footnotetext{
11 "Lo che, achiunque vi rifleta, dee recar maraviglia come tutti i filosofi seriosamente se studiarono di conseguire la scienza di questo mondo naturale, del quale, perché Iddio egli il fece, esso solo ne há la scienza".

12 "Quello è degno d'osservazione: che ' $\mathrm{n}$ tutte le lingue la maggior parte dell'espressioni d'intorno a cose inanimate sono fatte com trasporti del corpo umano e delle sue parti e degli umani sensi e dell'umane passioni".

13 "Perché come la metafisica ragionata insegna che $<<$ homo intelligendo fit omnia $>>$, così questa metafisica fantasticata dimonstra che $<<$ homo non intelligendo fit omnia $>>$; e forse com più di verità
}

ZIR - A tese da primazia da metáfora, defesa e problematização... 
homem não ter acesso ao que seria uma essência exaustiva das coisas do mundo, na medida em que não foi ele quem as derradeiramente criou.

É preciso entender, por outro lado, que o mundo das nações não é a projeção transparente de uma natureza interior ao homem da qual ele teria a chave, pois a origem última dessa natureza interior também lhe permanece inacessível, tanto quanto a das coisas que lhe são exteriores. A natureza interna do homem, a alma, também só pode ser conhecida metaforicamente, pois a mente humana, "permanecendo imersa e sepulta no corpo, é naturalmente inclinada a sentir as coisas do corpo e tem de se esforçar e se fatigar muito para entender a si mesma, assim como o olho corpóreo, que vê todos os objetos que estão no seu exterior, e tem do espelho necessidade para ver a si mesmo" (1953, \$331) ${ }^{14}$. É no contato, entre uma natureza interna, cuja origem última lhe permanece inacessível, e uma natureza externa, cuja origem última também não lhe está acessível, que surge, para o homem, o mundo, permeado de metáforas e transposições, das nações, com todos os seus costumes, artes, ciências, linguagem.

Falta-nos mostrar agora como o mundo de uma dada nação, que é o mundo 'natural' daquela nação, permanece recôndito e dando sustentação a ela durante todo o seu subsequente desenvolvimento. Podemos compreender melhor o desenvolvimento desse mundo a partir de sua formação através de três tópicos que vamos a partir de agora explorar: o primado do social, a atividade perceptiva e os protótipos.

\subsection{O primado do social}

[...] a primeira ciência a ser ensinada deve ter sido a mitologia, isto é, a interpretação das fábulas (porque, como será visto, todas as histórias gentílicas tinham princípios fabulosos) [...]. E com um método feito dessa maneira, são reencontrados os princípios tanto das nações quanto das ciências, as quais surgem dessas nações [...]: como por toda essa obra será demonstrado que da pública necessidade ou utilidade dos povos eles [os princípios das

\footnotetext{
questo che quello, perché l'uomo com l'intendere spiega la sua mente e comprende esse cose, ma col non intendere egli di sé fa esse cose e, col transformandovisi, lo diventa".

14 " [...]la mente umana [...] restata immersa e seppellita nel corpo, è naturalmente inchinata a sentire le cose del corpo e dee usare troppo sforzo e fatiga per intendere se medesima, come l'occhio corporale che vede tutti gli obbietti fuori di sé ed há dello specchio bisogno per vedere se stesso".
} 
nações] tiveram seu começo, e não de outra forma, e depois, com o refletir de homens argutos e particulares, foram aperfeiçoados. $\mathrm{E}$ assim deve começar a história universal, que todos os doutos dizem faltar nos seus princípios. $(1953, \$ 51)^{15}$

Nessa passagem, vemos que Vico estabelece como uma das tarefas da Ciência Nova mostrar que os princípios que estão na base das histórias dos povos gentis eram fabulosos. Esses princípios teriam surgido em função do que era publicamente necessário e útil para essas sociedades. Somente depois, eles foram refinados por homens particulares que sobre eles refletiram. Para poderem se desenvolver, os homens têm fundamentalmente de se associar uns aos outros, pois nenhum homem sequer sobrevive isoladamente. A comunidade, por sua vez, estrutura-se através de histórias e mitos.

Nessas primeiras nações, assim como não existiam ideias abstratas, tampouco existia a noção de uma natureza humana comum. Os mais fortes percebiam-se com uma natureza diversa daqueles que eles dominavam. Vico acentua o caráter irrefletido, emocional e cruel dessas primeiras nações, referindo-se especificamente à história romana:

De modo que, porque os nobres dos povos primeiros se tinham por heróis, isto é, de natureza superior que a dos plebeus, [...] governavam tão mal a multidão pobre das nações. Porque certamente a história romana assombra qualquer leitor prudentíssimo, que a organize através das seguintes relações: que virtude romana com tanta soberba? Que moderação com tanta avareza? Que calmaria com tanta ferocidade? Que justiça com tanta desigualdade? $(1953, § 668)^{16}$

\footnotetext{
15 " [...] la prima scienza da doversi apparare sai la mitologia, ovvero l'interpetrazion delle favole (perché, come si vedrà, tutte le storie gentilesche hanno favolosi i princìpi), e che le favole furono le prime storie delle nazioni gentili. E com sì fatto metodo [son da] rinvenire i princìpi come delle nazioni così delle scienze, le quali da esse nazioni son uscite e non altrimenti: come per tutta quest'opera sarà dimostro ch'alle pubbliche necessità o utilità de' popoli élleno hanno avuto i lor incominciamenti, e poi, com applicarvi la riflessione acuti particolari uomini, si sono perfezionate. E quindi cominciar debbe la storia universale, che tutti i dotti dicono mancare ne'suoi princìpi".

16 “Talché per quest'istessochí nobili de'primi popoli si tenevano per eroi, ovvero di superior natura a quella dei lor plebei, come appieno sopra si è dimostrato, facevano tanto malgoverno della povera multitudine delle nazioni. Perché certamente la storia romana sbalordisce qualunque scortissimo leggitore, che la combinisopra questi rapporti: che romana virtùdove fu tanta superbia? Che moderazione dove tanta avarizia? Che mansuetudine dove tanta fierezza? Che giustizia dove tanta inegualità?".
}

ZIR - A tese da primazia da metáfora, defesa e problematização... 
Uma série de hábitos, um modo de vida precisou ser instaurado para que essas sociedades pudessem surgir:

[...] os princípios, os quais podem satisfazer uma tão grande maravilha, devem necessariamente ser estes: [...] a educação das crianças severa, áspera, cruel, tal como foi aquela dos lacedemônios, que foram os heróis da Grécia, os quais no templo de Diana batiam nos filhos até esses não poderem mais, de modo que caíam frequentemente mortos, convulsos de dor, sob o chicote dos pais, para que se habituassem a não temer dor e morte [...]. [...] Se adquiriam com os dotes heróicos as mulheres [...]. [...] Os jogos e os divertimentos eram fatigantes, como luta, corrida [...]; eram ainda perigosos, como duelos, caça de feras, pelo que se habituavam a firmar a força e o ânimo e a descuidarse e desprezar a vida. $(1953, \$ 669-73)^{17}$

Assim, o fundamento das nações e mesmo, mais tarde, das ciências está, para Vico, em sentimentos e hábitos, os quais surgem e se estruturam dentro de uma dada comunidade no início da sua organização. Esses sentimentos e hábitos se estruturam através de 'princípios fabulosos', que são as alegorias desenvolvidas nas mitologias. Somente depois que a comunidade se estabeleceu através desses 'princípios fabulosos', mitológicos, e sob esse pano de fundo, é que podem surgir outras atividades mais abstratas e individuais como a reflexão filosófica.

\subsection{A atividade perceptiva}

Vico expressa a relação entre poetas e filósofos por um outro ângulo, a saber, através de uma analogia com a complementaridade existente entre sentidos e intelecto na cognição humana individual:

\footnotetext{
17 "Laonde i princìpi, i quali possono soddisfare uma sì gran maraviglia, debbono necessariamente esser questi: [...] l'educazion de'fanciulli severa, aspra, crudele, quale fu quella degl'illiterati lacedemoni, che furono gli eroi della Grecia, i quali nel templo di Diana battevano i figliuli fin all'anima, talché cadevano sovente morti, convulsi dal dolore, sotto le bacchete de'padri, accioché s'avvezzassero a non temere dolori e morte; [...]. [...] Si comperino com le doti eroiche le mogli, [...]. [...] I giuochi e i piaceri sien faticosi, come lutta, corso [...]; sieno ancor com pericolo, come giostre, cacce di fiere, onde s'avvezzino a fermare le forze e l'animo e a strappazzare e disprezzare la vita".
} 
E por todo esse livro se mostrará que [com] aquilo que antes tinham sentido no que se refere à sabedoria vulgar os poetas, concordaram depois no que se refere à sabedoria esquecida [riposta] os filósofos; tal que se pode dizer aqueles terem sido o sentido e estes o intelecto do gênero humano; do que ainda em sentido geral seja verdadeiro aquilo que Aristóteles disse particularmente de cada homem: 'Nibil est in intellectu quin prius fuerit in sensủ, isto é, que a mente humana não entenderia aquilo que não tivesse tido alguma causa (que os metafísicos hoje chamam 'circunstância') nos sentidos. A qual [mente humana], por isso, usa o intelecto quando, das coisas que sente, recolhe coisa que não cai sob os sentidos, o que propriamente no latim quer dizer 'intelligere'. $(1953, \$ 363)^{18}$

Dentro dessa analogia, não obstante a complementaridade nela envolvida, Vico afirma terem os poetas precedido os filósofos, porque sentiram, antes, aquilo que só mais tarde seria objeto de reflexão filosófica, quando já em parte, ao menos, esquecido (riposto). A analogia ilumina a relação entre os poetas e os filósofos apenas em parte, pois, dentro da complementaridade entre sentidos e intelecto que possibilita o conhecimento para cada indivíduo, não se pode falar que os sentidos de fato precedam o intelecto. Nos momentos cognitivos, ambos estão em ação. Nesses momentos, segundo o próprio Vico, numa passagem na obra Dell'Antichissima Sapienza Italica ${ }^{19}$, anterior à Ciência Nova, ocorre que determinados elementos das coisas, dados nos sentidos, vão sendo recolbidos pela mente até que se geram ideias:

De outra parte, como as palavras das ideias, assim as ideias são símbolos e caracteres das coisas: do que deriva que, da maneira mesma que 'legere' se diz daquele que vai recolhendo os elementos da escrita com os quais se compõe a palavra, assim 'intelligere' é dito de quem vai recolhendo, de uma coisa, todos os elementos

\footnotetext{
18 "E per tutto questo libro si mostrerà che quanto prima avevano sentito d'intorno alla sapienza volgare i poeti, tanto intesero poi d'intorno alla sapienza riposta riposta i filosofi; talché si possono quelli dire essere stati il senso e questi l'intelletto del gener umano; di cui anco generalmente sai vero quello da Aristotile detto particolarmente de ciascun uomo: 'Nibil est in intellectu quin prius fuerit in sensu', cioè che la mente umana non intenda cosa della quale non abbia avuto alcun motivo (chí metafisici d'oggi dicono 'occasione') da' sensi, la quale allora usa l'intelletto quando, da cosa che sente, raccoglie cosa che non cade sotto de' sensi; lo che propriamente a'latini vuol dir 'intelligere"'.

${ }^{19}$ A ser referida a partir de agora pela nossa abreviação 'DA'.
}

ZIR - A tese da primazia da metáfora, defesa e problematização... 
aptos a exprimir uma ideia perfeitíssima. (VICO, DA, 1953, p. $248)^{20}$

A 'ideia perfeitíssima', ou (na passagem da Ciência Nova, citada antes) 'a coisa que não cai sob os sentidos', se dá com base na experiência sensível, mas é também em parte um ultrapassar da experiência sensível. Esse ultrapassar é caracterizado por Vico, numa passagem da Risposta all'articolo X del tomo VIII del 'Giornale de'letterati d'Italia'21, como o acréscimo (poderíamos dizer qualitativo) ou a perfeição obtida como resultado de uma tarefa de seleção:

[...] a palavra 'intelligere' não vem de 'intus legere', que seria 'recolher internamente' [...], mas vem de 'interlego' [escolher, selecionar], feito mais doce 'intellego', tomada a preposição 'inter', não no sentido de entremear coisas, mas sim como se significasse 'selecionar dentre muitas as melhores coisas', isto é, dizer as verdades, mas com o significado de acréscimo ou de perfeição, como o demonstram os termos 'interminare', ameaçar fortemente; 'intermortuus', totalmente morto; [...] 'interdicere', ordenar abertamente. (VICO, RGI, 1953, p. 343-344) ${ }^{22}$

Para que os poetas não sejam caracterizados como permanecendo num estado pré-intelectual, no qual não houvesse atividade cognitiva, teria de ocorrer que o intelligere, como atividade característica da cognição humana, também já estivesse lá, de alguma forma, no início do mundo das nações, com os poetas. Tanto poetas quanto filósofos trabalhariam, assim, fazendo uso dos sentidos e do intelecto, pois não há atividade cognitiva, rigorosamente falando, sem a cooperação dessas 'faculdades'.

20 'D'altra parte, come le parole delle idee, così le idee sono simboli e caratteri delle cose: donde deriva che, alla guisa medesima che 'leggere' si dice di colui che va raccogliendo gli elementi della scrittura com i quali si compongono le parole, così 'intelligere' vien detto di chi va raccogliendo, di uma cosa, tutti gli elementi atti ad esprimerne un' idea perfettissima".

${ }^{21}$ A ser referida a partir de agora pela nossa abreviação 'RGI'.

22 ' "[...] la parola 'intelligere' non viene da 'intus legere', che sarebbe 'internamente raccogliere', [...] ma viene da 'interlego', fatto più dolce 'intellego', presa la preposizione 'inter', non in sentimento di frammezzamento, sì che significasse 'trascegliere tra le molte migliori cose', cioè a dire le vere, ma in significazione di accrescimento o di perfezione, come il dimostrano le voci 'interminar', minacciar fortemente; 'intermortuus', morto affato; [...] 'interdicere', apertamente ordinare (che non intendendo alcuni interpreti delle leggi, molto divagano dal vero d'intorno l'origene della voce 'inetrdictum')". 
No que consistiria exatamente, então, a diferença entre poetas e filósofos, a primazia daqueles sobre esses, à luz dessa analogia com a complementaridade entre intelecto e sentidos? Ela parece residir no fato de a força dos elementos sensiveis da atividade poética ser maior. Os poetas seriam os responsáveis por dar forma às experiências que serão a base do nosso conhecimento. Os filósofos trabalhariam com essas experiências já formadas, formatadas, somente depois que elas estivessem fixadas e estabilizadas na comunidade.

Podemos enfatizar no final deste ponto, mais uma vez, a contemporaneidade da abordagem de Vico. Conforme as explicações dadas por Vico com relação ao termo intelligere, poderíamos compreender a percepção como uma atividade gestáltica, na qual determinados elementos das coisas, dados nos nossos sentidos, são selecionados, de uma dada forma, pela mente, gerando ideias. Sendo assim, a abordagem de Vico evoca o modo como Lakoff e Johnson compreendem a percepção e a formação de conceitos (1980). Para esses autores, as experiências que estão na base da linguagem de uma determinada comunidade de seres humanos são estruturadas em termos de Gestalten. A estrutura dessas Gestalten são produto do nosso corpo, do nosso desenvolvimento e das nossas interações num dado ambiente físico e cultural.

Pode-se dizer, entretanto, que a abordagem de Vico parece possuir uma vantagem com relação à de Lakoff e Johnson. Tais Gestalten teriam de ser tomadas para Vico como já necessariamente metafóricas, nascendo de um atrito entre o externo e o interno, e de uma reelaboração seletiva de dados sensíveis pelo intelecto. Recorde-se aqui que a natureza interna do bomem lhe é em última instância tão desconhecida quanto a natureza das coisas externas. Esse ponto não é tão claramente colocado na abordagem de Lakoff e Johnson. Ao enfatizar certos esquemas (por exemplo, diferenças orientacionais entre acima e abaixo) como uma espécie de base emergindo diretamente da nossa experiência corpórea, Lakoff e Johnson correm o risco de solapar seu projeto inicial de conferir ao processo metafórico em si mesmo uma primazia fundamental (MAC CORMAC, 1985, p. 67-68; of. GLUCKSBERG; KEYSAR, 1990, p. 15). Como, para Vico, no fundo os homens não conhecem sequer sua própria natureza, ele se livra desse tipo de contradição. Tudo para o homem é dado a posteriori, depois de um choque entre coisas (dele mesmo e do mundo) cuja estrutura última ele não tem como conhecer. Nada emerge diretamente, tudo é fruto de um atrito. 


\subsection{Os protótipos}

De acordo com Vico, as leis mais antigas "vemo-las concebidas comandando ou vetando a um só". Elas passavam a valer "para todos em seguida (de tal forma os primeiros povos eram incapazes de universais!)" (1953, \500)23. Entendemos aqui "incapazes de universais" no sentido de que essas "leis" não seriam a rigor abstratas. Pelo contrário, elas se vinculariam sempre a casos particulares. Esse caráter não abstrato e particularizado será melhor explicado ao longo dos parágrafos seguintes. Deve-se considerar, contudo, que, seja como for, esses casos aos quais essas leis estariam vinculadas tinham uma força normativa (e portanto pretensão à universalidade), na medida em que funcionavam como exemplos. Vico prossegue:

[...] a lei de Túlio [contra Horácio/ Tito Lívio, I, 26] na verdade é um daqueles que se chamaram 'exempla', no sentido de 'castigos exemplares', e devem ter sido os primeiros exemplos que usou a razão humana (o que convém com aquilo que ouvimos de Aristóteles, que 'nas repúblicas heróicas não existiam leis a respeito dos erros e das ofensas privadas'); e, desta forma, primeiro existiram os exemplos reais, depois, os racionalizados, de que se servem a lógica e a retórica. $(1953, § 501)^{24}$

Ou seja, as leis mais antigas consistem no uso de determinados casos particulares como modelos, exemplos normativos, protótipos, para regrar a conduta dos seres humanos. Esses exemplos, contudo, permanecem muito presos às — mergulhados nas — circunstâncias concretas da ação. É aquele caso, na sua especificidade, que é usado, transportado como um modelo normativo, sobre outros casos, também particulares, específicos. Esse transporte de um caso particular sobre outro pode ser dito metafórico, na medida em que, entre o caso usado como exemplo e o caso a ser normatizado, existem, ambos tomados concretamente, elementos em parte comuns e em parte diferentes. Pela

\footnotetext{
23 "Perché l'antichissime leggi si osservano concepute comandando o vietando ad um solo, le quali poi correvan per tutti appresso (tanto i primi popoli eran incapaci d'universali!)".

24 "Ora, per ritornar al proposito, cotal legge di Tullo in fatti è uno di quelli che si dissero 'exempla' in senso di 'castighi esemplari', e dovetter esser i primi esempli ch'usò l'umana ragione (lo che conviene com quello ch'udimmo da Aristotile sopra, nelle Degnità: che 'nelle repubbliche eroiche non vi erano leggi d'intorno a'torti ed offese private'); e 'n cotal guisa, prima furono gli esempli reali, dipoi gli esempli ragionati de'quali si servono la logica e la rettorica”.
} 
relação que entre os dois casos é estabelecida, na qual um é compreendido em termos do outro (que a rigor é diferente dele), coordenam-se esses elementos numa dada direção. Essa direção poderá, mais tarde, pela repetição dessa coordenação, adquirir um sentido racionalizado, isto é, receber um nome independente, próprio, e se desligar de certa forma da concretude dos casos particulares aos quais diretamente se referia.

Vico afirma ainda o seguinte:

[...] os primeiros homens do paganismo eram de mente singularíssima, pouco menos que a das bestas, para as quais cada nova sensação cancela completamente a antiga (que é a razão por que [as bestas] não podem combinar ou discorrer), pelo que as sentenças todas deveriam ser singularizadas em relação àquele que as sentia. Assim, o sublime, que admira Diogini Longino [Pseudo Longino, De sublimitate, XI] na ode de Safo [...], que o enamorado, na presença da sua amada, explica por semelhança, Ille mi par esse deo videtur [Me parece ser semelhante a um deus], não tem o sumo grau da sublimidade, porque não singulariza a sentença em si mesmo, como faz Terêncio [Heautont., IV, 3, 15], ao dizer Vitam deorum adepti sumus [Alcançamos a vida dos deuses] [...]. Mas do mesmo poeta [Terêncio], numa outra comédia [Ecyra, $\mathrm{V}, 4,35]$, o mesmo sentimento é elevado ao sumo grau da sublimidade, quando, singularizando-o, o apropria àquele que sente: Deus factus sum [Tornei-me deus]. $(1953, \$ 703)^{25}$

A mente poética seria, segundo Vico, tão singular, que as sentenças por ela criadas se vinculariam com toda a força àquele que as profere - nisso consistiria o seu carácter mais sublime. Então, para se poder realmente compreendê-las, teríamos de nos colocar, por empatia, no lugar do sujeito da sentença, deixando em parte de sermos nós mesmos e tornando-nos em parte outro. Segundo outra passagem, "as

\footnotetext{
25 "Ora, perché i primi uomini del gentilesimo erano di menti singolarissime, poco meno che di bestie, alle quali ogni nuova sensazione cancella affatto l'antica (ch'è la ragione perché non possono combinar e discorrere), perciò le sentenze tutte dovevan essere singolarizzate da chi sentivale. Onde quel sublime, ch'ammira Dionigi Longino dell'oda di Saffo [...] che l'innamorato, alla presenza della sua amata donna, spiega per somiglianza: 'Ille mi par esse deo videtur', manca del sommo grado della sublimità, perché non singolarizza la sentenza in se stesso, come fa Terenzio, com dire: Vitam deorum adepti sumus [...]. Ma dallo stesso poeta, in altra commedia, il medesimo sentimento è innalzato al sommo grado della sublimità, ove, singolarizzandolo, l'appropia a chi 'l sente: Deus factus sum".
}

ZIR - A tese da primazia da metáfora, defesa e problematização... 
sentenças poéticas devem ser concebidas de paixões verdadeiras ou que por força de uma acesa fantasia se façam verdadeiramente sentir, e portanto devem ser individuadas naqueles que as sentem". As sentenças poéticas implicam, para serem adequadamente compreendidas, que $o$ sujeito se coloque num estado concreto de uma dada paixão. Elas não são como máximas que podem ser refletidas de forma neutra, pois sentenças poéticas exigem o deslocamento do sujeito para uma dada disposição. No mesmo parágrafo, Vico conclui: "pelo que definimos que as máximas de vida, porque são gerais, são sentenças dos filósofos; e as reflexões sobre as próprias paixões são [sentenças] de falsos e frios poetas" (1953, \825, grifo nosso). ${ }^{26}$ Os verdadeiros poetas são provocadores, fazem com que as coisas e os sujeitos se coloquem no lugar umas das outras e uns dos outros, abrindo, dessa forma, espaço para que ganhem sentido. Somente maus poetas, ou poetas tardios, permanecem no terreno firme da generalidade já alcançada, em que as coisas são remetidas igualmente a um conceito abstrato que as subsume mecanicamente. E o tempo dos maus poetas não é senão o tempo dos bons filósofos, mestres da ironia, sempre preocupados com a verdade ou falsidade de proposições:

A ironia certamente não pode ter iniciado senão ao tempo da reflexão, porque ela é formada do falso pela força de uma reflexão que assume uma máscara de verdade. [...] tendo sido os primeiros homens das nações pagãs simplíssimos como crianças, as quais por natureza são verdadeiras, as primeiras fábulas não poderiam fingir nada de falso; pelo que devem necessariamente ser narrações verdadeiras. $(1953, \$ 408)^{27}$

Por "tempo da reflexão" sugerimos que aqui se entenda o tempo da reflexão filosófica, quando a origem concreta das coisas, dos conceitos e da linguagem começa a ser esquecida (riposta). Nesse tempo,

\footnotetext{
26 'Egli è infin al cielo sublime nelle sentenze poetiche, ch'abbiam dimostrato, ne' Corollari della natura eroica nel libro secondo, dover esser concetti di passioni vere o che in forza d'un' accesa fantasia ci si facciano veramente sentire, e perciò debbon esser individuate in coloro che le sentono. Onde diffinimmo che le massime di vita, perché sono generali, sono sentenze di filosofi; e e riflessioni sopra le passion medesime sono di falsi e freddi poeti".

27 ' 'L'ironia certamente non poté cominciare che da' tempi della riflessione, perch'ella è formata dal falso in orza d'uma riflessione che prende maschera di verità. E qui esce um gran principio di cose umane, che conferma l'origine della poesia qui scoverta: che i primi uomini della gentilità essendo stati semplicissimi quanto $i$ fanciulli, $i$ quali per natura son veritieri, le prime favole non poterono fingere nulla di falso; per lo che dovettero necessariamente essere, quali sopra ci vennero diffinite, vere narrazioni”.
} 
as coisas, os conceitos e a linguagem não se apresentam mais numa vinculação fundamental com aquelas experiências concretas que as estabeleceram, na comunidade de uma dada nação. Eles podem então ser ironicamente deslocados para significar o que não são. No início, isso não era possível. As metáforas e os mitos emergem como os referenciais, e só perdem o seu caráter normativo com relação ao que são as coisas à medida que sua repetição vai anulando, ao longo do tempo, a força daqueles elementos e da gênese que os compôs numa determinada forma. Assim, chega um momento em que não se precisa mais contar, imitar, rememorar as peripécias envolvidas no mito de Hermes Trimegistro para se entender o que seja a 'sabedoria civil'. A 'sabedoria civil' emerge, então, ela própria como um gênero abstrato 'desvinculado' de qualquer caso específico que ela venha a representar. Ao mesmo tempo, talvez agora ela passe a ter um significado recôndito, sujeito a certos deslocamentos em relação ao que era na origem.

\section{CONSIDERAÇÕES FINAIS}

Segundo a perspectiva de Glucksberg e Keysar, já analisada, as metáforas podem ser consideradas sentenças de inclusão em classes que envolvem duas coisas diferentes e muitas vezes concretas, uma delas funcionando como um protótipo. Para Vico, todas as categorias que estão na base não apenas da linguagem, mas também do pensamento de uma dada comunidade, provêm do alinhamento entre experiências concretas (externas e internas, cuja natureza última permanece desconhecida), através de protótipos construídos pela imaginação e determinados pelo contexto em que essa comunidade se forma. Vico parece inclusive escapar de uma contradição que ameaça solapar a teoria de Lakoff e Johnson (MAC CORMAC, 1985, p. 67-8; $c f$. GLUCKSBERG; KEYSAR, 1990, p. 15). Ao contrário desses últimos autores, ele não apoia sua tese da primazia da metáfora numa espécie de base emergindo diretamente da nossa experiência corporal. A natureza interna do homem é em última instância tão desconhecida quanto a natureza das coisas externas, e ambas emergem conjuntamente num atrito. Conforme a máxima já citada no início da seção 2, para Vico, “o homem [...] não

ZIR - A tese da primazia da metáfora, defesa e problematização... 
entendendo, de si mesmo faz as coisas, e transformando a si mesmo, torna-se elas" (1953, \$405, ênfase nossa)..$^{28}$

Somente num segundo momento surgem os termos abstratos, designadores de classificações já cristalizadas, quando o enraizamento dos significados no corpo e na cultura dos homens de uma dada nação começa a ser progressivamente esquecido. A linguagem metafórica não é um desvio da linguagem literal, mas é a ferramenta através da qual toda linguagem é construída. Assim, com base no pensamento de Vico, se poderia responder afirmativamente à pergunta colocada por Ricoeur em um de seus artigos enfocando a metáfora:

Se a metáfora pertence a uma heurística do pensamento, não poderíamos imaginar que o processo que perturba e desloca uma certa ordem lógica, uma certa hierarquia conceitual, um certo esquema classificatório, é o mesmo que aquele do qual todas as classificações procedem? (RICOEUR, 1996, p. 335 - tradução nossa)

\section{Ricoeur continua:}

Certamente, a única função da linguagem da qual estamos a par opera dentro de uma ordem já constituída; a metáfora só produz uma ordem nova ao criar fendas na ordem antiga. Entretanto, não poderíamos imaginar que a ordem, ela mesma, nasce do mesmo modo como se modifica? Não existiria, nos termos de Hans-Georg Gadamer, um processo metafórico trabalhando na origem do pensamento lógico, na raiz de todas as classificações? Essa é uma hipótese de mais longo alcance que aquelas que pressupõem uma linguagem já constituída dentro da qual a metáfora operaria. (RICOEUR, 1996, p. 335 - tradução nossa)

Segundo o que vimos anteriormente, o homem poderia ser considerado, na perspectiva de Vico, exatamente um 'criador de segunda ordem', na medida em que ele recria, metaforicamente, as coisas do mundo que lhe é dado (cuja origem última está num plano divino, derradeiro desencadeador dos seres), gerando uma nova ordem, o mundo de uma dada nação. Os mundos das várias nações não apenas

\footnotetext{
28 "Perché come la metafisica ragionata insegna che $<<$ homo intelligendo fit omnia $>>$, così questa metafisica fantasticata dimonstra che $<<$ homo non intelligendo fit omnia $>>$; e forse com più di verità questo che quello, perché l'uomo com l'intendere spiega la sua mente e comprende esse cose, ma col non intendere egli di sé fa esse cose e, col transformandovisi, lo diventa”.
} 
'surgem', mas são provocados, quando os homens colocam em contato, deslocando e transpondo, elementos desconhecidos tanto da sua própria natureza interna quanto de uma natureza externa.

Assim, a primazia da metáfora, mais do que inverter a tese tradicional, postulando, por sua vez, a linguagem literal como 'desvio' da metafórica, parece abalar as distinções entre 'literal' e 'figurativo'. Valendo-nos de novo das palavras de Ricoeur: "A idéia de um impulso metafórico inicial destrói estas oposições entre próprio e figurativo, ordinário e estranho, ordem e transgressão" (RICOEUR, 1996, p. 335, tradução nossa). A metáfora é, assim, a própria força que faz nascer a linguagem. O literal, por sua vez (com sua correspondente noção de metáfora como desvio) ocorre quando as coisas, os conceitos e a linguagem em geral de uma nação "perdem" sua vinculação com as experiências concretas que os estabeleceram.

A tese da primazia da metáfora perturba e coloca em jogo algumas noções caras à tradição filosófica, como a visão de que o conhecimento nos revelaria algo a respeito do que as coisas seriam, independentemente de como esse próprio conhecimento as conforma, segundo fatores associados ao seu contexto. Ela abala a distinção entre uma função descritiva e uma função modeladora da linguagem. Por isso, aqueles estudiosos, das mais diversas áreas, hoje em dia preocupados em investigar os aspectos pragmáticos e retóricos do conhecimento, podem encontrar em Vico uma rica fonte para pesquisa. Deve-se ter em mente, entretanto, conforme a problematização aqui discutida, que não se trata de um convite à simples inversão de posições mais tradicionais. Assim como a tese da primazia da metáfora, se bem entendida, demanda não apenas uma inversão da tese tradicional da metáfora como desvio, mas uma reconsideração da própria distinção entre o metafórico e o literal, a ênfase nos aspectos pragmáticos e retóricos do conhecimento deveria resgatar esses aspectos não enquanto meramente opostos a critérios de verdade de ordem epistemológica. Como vimos em Vico, enquanto figura retórica fundamental, a metáfora de fato institui critérios, sem os quais não seria possível sequer a existência e manutenção de qualquer comunidade linguística. A chave dessas questões parece estar na flexibilização ou mesmo superação (antes do que mera inversão) de uma série de dicotomias, entre as quais estão não apenas figurativo/literal, retórica/epistemologia, mas também ficção/verdade, físico/mental, etc. 


\section{REFERÊNCIAS}

BLACK, M.. Metaphor. In: JOHNSON, M. (Ed.). Philosophical perspectives on metaphor. Minneapolis: University of Minnesota Press, 1981. p. 63-75.

COOPER, D. E. The primacy of metaphor. In: . Metaphor. Oxford: Basil Blackwell, 1986. p. 257-79.

GLUCKSBERG, S.; KEYSAR, B. Understanding metaphorical comparisons: beyond similarity. Psychological rewiew, v. 97, n. 1, p. 3-18, 1990.

LAKOFF, G.; JOHNSON, M. Metaphors we live by. Chicago: Chicago University Press, 1980.

MAC CORMAC, E. R. A cognitive theory of metaphor. Cambridge: MTTT Press, 1985.

RICHARDS, I. A. The philosophy of rhetoric. In: JOHNSON, M. (Ed.). Philosophical perspectives on metaphor. Minneapolis: University of Minnesota Press, 1981. p. 48-62.

RICOEUR, P. Between rhetoric and poetics. In: ___ Essays on Aristotle's rhetoric. Berkeley: University of California Press, 1996. p. 324-84.

VICO, G. Opere. Milano: Riccardo Ricciardi Editore, 1953.

Recebido em 18/06/07. Aprovado em 20/08/08.

Title: The thesis of the metaphor primacy, defense and problematization: a study based on Vico

Author: Alessandro Zir

Abstract: This paper sustains, on the basis of the work of the modern Italian philosopher Giambattista Vico, a thesis which characterizes poetic and metaphorical language as our primary language. Considering the contribution of some up-to-date authors to the subject, we will also take into consideration the contemporaneity of Vico's approach. The view of metaphoric language as our primary social language was formulated by Giambattista Vico in his work Principii di Scienza Nuova. According to him, the language of a community emerges from the contact between everything that is immediately close to its concrete human beings and the things of an external world. The community does not have a conscious knowledge either of the external things or of what is closer to them, such as their own emotions and bodies. The contact between these two loci (internal and external) of things and meanings is then full of fantasy and imagination. The notion of an 'abstract language' and the distinction between what is 
metaphorical and what is literal arises only later, when the stabilization of meanings in the imaginative production of a specific culture comes to be forgotten and these meanings are presumed to belong to the things themselves, objectively.

Keywords: knowledge; language; metaphor; Rhetoric; meaning.

Titre: La thèse de la primauté de la métaphore, défense et problématisation: une étude à partir de Vico

Auteur: Alessandro Zir

Résumé: Ayant comme base la pensée du philosophe italien moderne Giambattista Vico, cet article fait la défense de la thèse qui caractérise le langage poétique et métaphorique comme si c'était le premier langage. Tout en considérant des contributions pour le sujet de quelques auteurs actuels, on vise aussi la contemporanéité de Vico. La notion du langage métaphorique comme premier langage a été formulée par Giambattista Vico dans son œuvre majeure, Principii di Scienza Nuova. Selon lui, le langage d'une communauté apparaît à partir d'un contact, chargé de fantaisie et d'imagination, parmi tout ce qui est tout de suite proche aux êtres concrets, comme leurs émotions et leurs corps, qui ne sont pas à la fin connus par lui, et les choses d'un monde extérieur aussi inconnu. Le 'langage abstrait' et la distinction entre le métaphorique et le littéral surgissent seulement plus tard, quand cet enracinement des significations dans l'éclosion imaginative d'une culture spécifique est oublié et pris comme appartenant seulement aux choses dans elles- mêmes, objectivement.

Mots-clés: connaissance; langage; métaphore; Rhétorique; signification.

Título: La tesis de la preponderancia de la metáfora, defensa y problematización: un estudio a partir de Vico

Autor: Alessandro Zir

Resumen: Este artículo defiende, con base en el pensamiento del filósofo italiano moderno Giambattista Vico, la tesis que caracteriza el lenguaje poético y metafórico como siendo el lenguaje primero. Considerando contribuciones de algunos autores actuales para el tema, se apuntará igualmente para la contemporaneidad del abordaje de Vico. La noción del lenguaje metafórico como lenguaje primero fue formulada por Giambattista Vico en su obra Principii di Scienza Nuova. De acuerdo con él, el lenguaje de una comunidad surge de un contacto, cargado de fantasía e imaginación, entre todo lo que está inmediatamente próximo a los seres humanos concretos, como sus emociones y sus cuerpos, que no son verdaderamente conocidos por él, y las cosas de un mundo externo también desconocido. El 'lenguaje abstracto' y la distinción entre lo metafórico y lo literal surgen apenas más tarde, cuando esa raigambre de los significados en la eclosión imaginativa de una cultura específica pasa a ser olvidado y es tomado como perteneciendo apenas a las cosas en ellas mismas, objetivamente.

Palabras-clave: conocimiento; lenguaje; metáfora; Retórica; significado.

ZIR - A tese da primazia da metáfora, defesa e problematização... 